\title{
Tecendo comentários ao artigo "Redescobrindo a família rural brasileira", de Mauro Almeida
}

(D) Verena Sevá'

Orcid: https://orcid.org/0000-0002-6961-097X

(D) Diego Amoedo"

Orcid: https://orcid.org/0000-0001-8268-0107 DOl: 10.17666/bib9705/2022
Submetido em 03/02/2022

Aceito em: 03/05/2022

O artigo "Redescobrindo a família rural brasileira", de Mauro Almeida, publicado em 1986, nos permite traçar múltiplas leituras, linhas de fuga e pontos de conexão - por isso chamamos este trabalho de "tecendo e desdobrando comentários" com o que podemos chamar de estudos de antropologia brasileira, teoria social, estudos de campesinato, organização social e parentesco, teoria econômica camponesa, estudos demográficos etc. Imersa na grande abrangência temática e teórica desse texto esconde-se sua potência que, razão pela qual, sem medo a exagero, podemos considerá-lo um clássico para todas aquelas pessoas que estejam interessadas em qualquer uma das linhas de reflexão acimas mencionadas.

Como bem enunciado, já no título, afinal de contas do que se trata é de redescobrir a família rural. E, num movimento similar ao que Edmund Leach faz em seu célebre ensaio "Repensando a Antropologia" (1961), Mauro Almeida nos mostra como existe rendimento analítico via noção de família e suas derivações.

O artigo se propõe a uma revisão crítica da literatura sobre família rural, especialmente brasileira e latino-americana, apontando, à época, para olhares inéditos sobre o tema e problematizando grandes narrativas. Posteriormente, Almeida retoma esse debate no ensaio "Narrativas agrárias e a morte do campesinato", publicado em 2007, na revista Ruris. Nele, as grandes narrativas teóricas sobre o campesinato são rechaçadas e, em seu lugar, é desnudado um mundo rural marcado por identidades sociais e étnicas plurais.

\footnotetext{
' Professora da Unidade Acadêmica de Ciências Sociais da Universidade Federal de Campina Grande (UFCG). E-mail: verenaseva@gmail.com.

" Professor da Universidade Federal do Oeste do Pará (UFOPA) no curso de Antropologia, do Programa de Antropologia e Arqueologia. E-mail: amoedo.diego@gmail.com.

Publicado em: março de 2022 | pp. 1-28
} 
Voltando ao artigo que estamos a comentar, trabalharemos a partir das cinco partes em que está organizado. A primeira opera como uma espécie de introdução e ajuda a mostrar a abrangência terminológica de conceitos como família, rural e campesinato. Exercício indispensável da disciplina antropológica, essa parte gira à volta do que podemos pensar como família, ou do que estamos entendendo quando falamos em famílias rurais. Famílias rurais que, nos anos 1970, ganharam destaque no campo da sociologia e da antropologia econômica ao trazerem para o debate o papel da pequena produção agrícola para o processo de acumulação capitalista nacional. Nesse cenário, Almeida aponta para um trânsito nas pesquisas, desde um momento inicial, cuja preocupação eram as relações de produção, para um olhar mais holístico e atento, voltado para as relações em torno da casa, do quintal e do roçado familiar.

Um deslocamento no olhar que vem acompanhado da problematização dos próprios conceito e papel de família rural no debate socioantropológico. De um lado, enumera estudos com viés econômico, preocupados em situar a família rural como unidade de produção (e consumo) para o capital ou como um modo de produção familiar dotado de uma lógica própria, que acaba por operar como resistência ante o avanço do capitalismo no campo, recusando a tese da diferenciação social do campesinato. De outro, nesse trânsito interpretativo, observa-se um redirecionamento de foco para elementos de âmbito extraeconômico, que procuram estudar a família rural como uma entidade em si mesma, e o seu trabalho como elemento para sua reprodução social, não o contrário. Grosso modo, Almeida sinaliza para mudanças interpretativas e conceituais sobre família rural, nas quais seus modos de trabalhar, suas estratégias de vida e sua existência social e identitária deixam de ser percebidos como resquícios num mundo da agricultura empresarial e do setor econômico urbano, no sentido de um "saco de pancadas" da sociedade capitalista, para ser redescoberta como uma força social de resistência às mudanças impostas ao campo pelo capitalismo moderno. E, nesse processo, os cálculos e as estratégias de reprodução social alicerçadas na tradição e na lógica do parentesco ganham lugar ante uma lógica exclusivamente econômica.

Um segundo movimento, Família, grupo doméstico, nos coloca no trilho de duas possíveis saídas conceituais que, umas vezes aproximam a noção de família a de grupo doméstico, e outras dela a distinguem. Ao tomarmos a noção de grupo doméstico, a centralidade está no grupo "familiar" correspondente a uma unidade residencial e de consumo, que quase sempre o é também de trabalho. Já a noção de família rural indica um grupo de parentes que pode ou não residir numa mesma casa, e compor ou não uma unidade de trabalho familiar, também chamada por Almeida como unidade técnica.

Na terceira parte, Economia doméstica, a questão circunda o protagonismo da família na organização e no controle do trabalho na unidade familiar. Não obstante, um protagonismo que não se confunde com a independência da família em relação a todo o processo produtivo: organização do trabalho na família, consumo familiar e comercialização dos produtos. Lado a lado a situações empíricas, majoritariamente estudadas até os anos 1980 no Brasil, de famílias camponesas compostas por pequenos proprietários de terra ou arrendatários, que utilizam em regra a mão de obra familiar, saberes tradicionais e pouco capital, e que detêm maior grau de independência funcional, Almeida chama a atenção para um número menor - embora não menos importante - de pesquisas sobre famílias rurais que, embora atuando como uma unidade técnica familiar (trabalham "em 
família"), não têm controle sobre o seu trabalho, como, por exemplo, os colonos do café do Sudeste Brasileiro, estudados por Verena Stolcke (1985), ou os moradores dos engenhos do Nordeste Brasileiro presentes nas reflexões de Lygia Sigaud (1981) e de Afrânio Garcia Júnior (1983).

Nessa seção, Almeida adentra a tese da economia camponesa de Chayanov, em que, para além de uma discussão de independência da família camponesa aos mandos e desmandos do capital, esse autor defende a existência ou coexistência de configurações que oscilam das formulações teóricas para tratar de forma similar unidades técnicas e unidades econômicas. As noções de equilíbrio e racionalidade camponeses de Chayanov (1974), explicativas do cálculo de trabalho e consumo da família camponesa, fazem-se presentes na reflexão sobre unidades familiares de seringueiros, pois a configuração da colocação, como na tese chayanoviana, é alvo constante de reconfigurações de estratégias de produção e reprodução de uma forma de vida. Propõe Almeida que a dinamicidade das configurações sociais poderia também ser repensada à luz dessa formulação de Chayanov. Van der Ploeg faz esse movimento quando retoma o autor russo e o recoloca no centro das tramas de transformações dos mundos rurais contemporâneos, apelando para a noção de recampesinização (Van der Ploeg, 2016) como mais uma forma de se pensar os camponeses como agentes dentro dos múltiplos processos de financeirização, mercado e de conectividade com o mundo.

Nessa problematização, e a partir de uma base empírica, como é a pesquisa que o professor desenvolveu com os seringueiros do Juruá (Almeida, 1993), que difere dos estudos clássicos postos em diálogo no texto que estamos comentando, tem lugar a redescoberta da família rural, ou das famílias rurais. Para quem leu a tese de Mauro Almeida, são perceptíveis os paralelos e tensões entre as noções de família e economia, pois trata de forma profunda a economia das colocações que neste ensaio ele chama de economia doméstica. O tema da economia camponesa de Chayanov permite ao autor pensar as estratégias de produção e reprodução dos grupos domésticos ou das famílias na floresta amazônica. Na tese, Almeida avança, com base na teoria da economia moral proposta por James Scott (1976), às diferentes configurações sociais e racionalidades que perpassam os momentos históricos por que passaram os seringueiros, contemplando desde os seringueiros explorados via dívida constante para com os patrões, e vinculados ao capital financeiro internacional, até um grupo social que se apoiou no conhecimento dos indígenas para constituir um sistema particular à volta das colocações e dos rios, compondo-se como um campesinato da floresta (Almeida, 1993), que reúne os conhecimentos dos camponeses do sertão com os povos indígenas da região.

$\mathrm{Na}$ quarta parte, sobre os Modelos Cognitivos, Chayanov e a teoria econômica camponesa continuam sendo centrais, mas aqui o autor complexifica o debate trazendo seu amplo conhecimento de múltiplos contextos etnográficos, especialmente amazonense/acreano, para desmobilizar as amarras fixadoras do caráter hermético dessas teorias. Defende que avancemos sobre as generalizações presentes nas teorias da economia camponesa e na definição de família rural, enquanto unidade técnica de trabalho independente e funcional, para descobrirmos a família rural, para além de seu papel de unidade de trabalho agrícola (unidade técnica), em relação a todas as dimensões da vida: social, cultural e política. Em outras palavras, propõe que não consideremos as famílias rurais 
somente a partir do seu ciclo de produção anual (ciclo curto), mas como reprodutoras de si mesmas (ciclo longo de reprodução).

Ademais, Almeida chama a atenção para os processos sociais que há por trás das diferentes configurações sociais familiares. Destaca na literatura a presença de uma normativa cultural e de uma ideologia camponesa estruturantes das ações e práticas de uma família camponesa idealizada, formada por núcleos familiares neolocais de proprietários ou arrendatários de terra, independentes, e organizados por uma autoridade hierárquica paterna. Por outro lado, repensa a partir de uma outra série de etnografias feitas por mulheres, que aportam dados de outras dimensões da vida familiar camponesa até então negligenciadas, como a invisibilidade do trabalho feminino e dos filhos, e o trabalho fora de casa realizado por parte da família camponesa. Dimensões e enfoques que passaram a ser lugar comum em importantes estudos sobre família e parentesco a partir dos anos 1990, como no estudo sobre família rural e parentesco de Ellen Woortmann (1995), e nas pesquisas de Maria José Carneiro (1996) e de Anita Brumer (2000), sem a pretensão de esgotar toda uma bibliografia mais recente e importante sobre o tema.

Já na quinta parte, Grupos locais, parentesco, casamento, é recolocada a problematização da não coincidência necessária entre família rural e grupo doméstico, antecipando a conclusão do texto sobre a existência de uma densa rede de relações e configurações sociais particulares, que expande a noção de família para além do grupo doméstico em contextos que ser e estar como parente não são a mesma coisa. Assim, noções como vizinhar e compadrio, tão caros à antropologia, retomam seu lugar de destaque ampliando as formulações e os modelos explorados até aquele momento. Nesse tópico, dialogamos com o clássico estudo de Ellen Woortmann (1995), intitulado Herdeiros, parentes e compadres, em que a autora nos remete a uma distinção importante entre as noções de parente e primo, verificada num contexto de campesinato sergipano, para explicar as diferentes formas de acesso aos recursos do território familiar (do Sítio). Segundo autora, parente é todo aquele familiar que compartilha de uma mesma descendência, de um mesmo sangue, enquanto primo é aquele que além de compartilhar o mesmo sangue, mora na terra familiar e, por isso, tem direito a usar os recursos do lugar, terra e água. Num sentido análogo, Godoi (1999) nos remete a uma parentela pesquisada por ela no Piauí, onde a distinção recai entre os parentes do lugar, os que vivem e trabalham na terra familiar, e os parentes ausentes, os que estão a viver fora dali, gerando, analogamente ao verificado por Woortmann, diferentes formas de acesso à terra familiar. Estamos a falar, portanto, de configurações familiares que existem e se reproduzem fora dos limites do grupo doméstico e da morada em comum, seja numa mesma casa ou num mesmo território de parentes (Sítio).

Aparecem nesse apartado também as noções de política local e de terra para se pensar as configurações camponesas do Brasil. Entram em cena, após ter discutido família, grupo doméstico, economia, ideologia e casamento, para ser o modulador e a chave analítica para compreensão das famílias rurais, seja enquanto coalizões políticas de grupos ligados por parentesco, seja como famílias extensas ou grupos extradomésticos mobilizados, reunidos e reproduzidos em razão de uma unidade socioterritorial (terra) que se quer conquistar, organizar ou defender coletivamente. 
Sobre este último aspecto, em específico, remetemos novamente o leitor para o supracitado ensaio de Mauro Almeida (2007), que destaca a centralidade do elemento terra como elemento estruturador de novas identidades políticas e sociais, baseadas em grande medida por grupos familiares que vieram a se constituir e/ou ter visibilidade após a reabertura política brasileira, em meados dos anos 1980. Citamos, por exemplo, o reconhecimento de terras de remanescentes de quilombos, as terras indígenas, os assentamentos rurais provenientes dos movimentos de luta por terra, as comunidades de fundo de pasto do Nordeste e os faxinais do sul do Brasil, os ribeirinhos, os seringueiros, as quebradeiras de coco, os pescadores artesanais, sem esgotar o elenco. Ademais, a visibilidade de outras antigas formações socioterritoriais antes invisibilizadas na política e no imaginário social, como as terras de preto, as terras de santo, as terras de índio, para citar algumas (Berno de Almeida,1989).

Para concluir, gostaríamos de apresentar alguns elementos relacionados à repercussão e à atualidade dos apontamentos feitos pelo professor Almeida. O tema das categorias continua sendo um grande e denso campo de discussão. Assim, consideramos que "Redescobrindo a família rural brasileira" é um aporte teórico e metodológico central, que nos mostra a importância de complexificar as categorias, e como isso deve ser feito, desde um enfoque teórico tensionado pelas etnografias. As categorias não operam como uma forma cristalizada de realidades empíricas. As categorias e as teorias são complexificadas à luz dos dados etnográficos, como bem apontou já Saez (2013). Nesse sentido, pensar a família rural não é definir um modelo normativo aplicável à realidade, mas tê-la como ponto de partida ou vértice para traçarmos linhas de raciocínio que nos ajudem a entender os processos sociais que estão sendo pautados pelos trabalhos de campo, conformando-se como novos modelos teórico-explicativos.

Nesse artigo, o professor Almeida propõe uma leitura e um debate teórico sobre a ampla temática da noção de família no que se pensa como contextos rurais. Traça linhas de raciocínio que promovem um deslocamento da noção de família rural e unidade de trabalho para um agrupamento doméstico e extradoméstico, que se pensa e que deve ser pensado para além do trabalho agrícola, embora esteja organizado muitas vezes em meio e a despeito dele, bem como por regras de parentesco consanguíneo e/ou ritual. Apesar de ser um texto seminal, não consideramos - aqui pensamos que o autor concordaria com esta afirmação -, que esse seja um debate esgotado, como vimos com as novas formulações que giram à volta do tema da família rural, como as noções de vicinalidade (PinaCabral, Godoi, 2014), casa (Marcelin, 1999) ou parentesco (Sahlins, 2013) que, necessariamente, precisam retornar a essa bibliografia clássica, para nela se apoiar e reformular conceitos e categorias.

\section{REFERÊNCIAS BIBLIOGRÁFICAS:}

ALMEIDA, Mauro William Barbosa de. (1993), Rubber tappers of the upper Juruá river, Brasil: The making of a forest peasantry. Tese de doutorado. University of Cambridge, Cambridge.

ALMEIDA, Alfredo Wagner Berno de, (1989), "Terras de Preto, Terras de Santo e Terras de Índio: uso comum e conflito", in CASTRO, Edna R. de; HÉBETE, Jean (org.), 
Na trilha dos grandes projetos: modernização e conflito na Amazônia. Belém, Cadernos do NAEA, 10.

BRUMER, Anita, (2000), "Gênero e agricultura: a situação da mulher na agricultura do Rio Grande do Sul", in XXI Congresso Internacional da Latin America Studies Association (LASA), Miami.

CARNEIRO, Maria José, (1996), "Esposa de agricultor na França", Revista Estudos Feministas, 4, 2:238-354.

CHAYANOV, Alexander V., (1974), La organización dela unidad económica campesina. Buenos Aires, Ediciones Nueva Visión.

GARCIA JR., Afrânio, (1983), Terra de trabalho. Rio de Janeiro, Paz e Terra.

GODOI, Emília Pietrafesa de, (1999), O trabalho da memória: cotidiano e história no sertão do Piauí. Campinas, Editora da Unicamp.

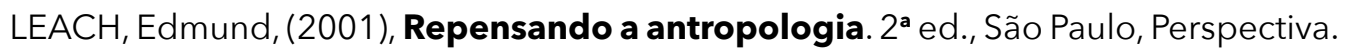

MARCELIN, Louis Herns, (1999), "A linguagem da casa entre os negros no Recôncavo Baiano", Mana, 5, 2:31-60.

PINA-CABRAL, João de; GODOI, Emília Pietrafesa de, (2014), "Apresentação: Dossiê Vicinalidades e Casas Partíveis", Revista de Antropologia, 57, 2:11-21. Disponível em https://www.revistas.usp.br/ra/article/view/89105, consultado em 1 fev. 2022. DOI: 10.11606/2179-0892.ra.2014.89105.

SAHLINS, Marshall, (2013), What kinship is... and is not. Chicago, The University of Chicago Press.

SAEZ, Oscar, (2013), Esse obscuro objeto de pesquisa: um manual de método, técnicas e teses em antropologia. Ilha de Santa Catarina, Ed. do Autor.

SCOTT, James C., (1976), The Moral Economy of the Peasant: Rebellion and Subsistence in Southeast Asia. New Haven; London, Yale University Press.

SIGAUD, Lygia, (1981), "Trabalho assalariado e trabalho familiar no Nordeste". Anuário Antropológico, 79: 181-199.

STOLCKE, Verena, (1988), Coffee Planters, Workers and Wives: Class Conflict and Gender relations on São Paulo Plantations, 1850-1980. New York, St Martin's Press.

VAN DER PLOEG, Jan Douwe, (2016), Camponeses e a arte da agricultura: um manifesto Chayanoviano. São Paulo, UNESP; Porto Alegre: UFRGS.

WOORTMANN, Ellen F., (1995), Parentes, herdeiros e compadres: Colonos do Sul

e Sitiantes do Nordeste. São Paulo, Hucitec; Brasília, Edunb. 


\section{Resumo}

\section{Tecendo comentários ao artigo "Redescobrindo a família rural brasileira", de Mauro Almeida}

Trata-se de um comentário ao artigo "Redescobrindo a família rural brasileira", publicado por Mauro Almeida, em 1986, na Revista Brasileira de Ciências Sociais. A publicação se destacou à época e, ainda hoje mantém-se atual ao questionar noções centrais no estudo das populações do campo. Nosso objetivo foi retomar a problemática levantada por Almeida sobre a multiplicidade de usos analíticos que a noção de família rural tem, e propor um diálogo com trabalhos acadêmicos posteriores do autor e de outros cientistas sociais brasileiros, procurando mostrar a pertinência atual do debate. A redescoberta da família rural proposta no texto ora comentado continua sendo um referencial teórico e metodológico importante para pensarmos a diversidade de modelos e formas de organização das populações do campo, e para tensionarmos o uso de grandes narrativas e categorias analíticas herméticas na compreensão de uma humanidade plural

Palavras-chave: Estudos rurais, campesinato, família rural, grupos domésticos, economia camponesa.

\section{Abstract \\ Commenting on the article "Rediscovering the Brazilian Rural Family", by Mauro Almeida}

This is a comment on the article "Rediscovering the Brazilian rural family", published by Mauro Almeida, in 1986, in the Revista Brasileira de Ciências Sociais. The publication stood out at the time and, even today, remains current by questioning central notions in the study of rural populations. Our objective was to resume the problem raised by Almeida about the multiplicity of analytical uses that the notion of rural family has, and to propose a dialogue with later academic works by the author and other Brazilian social scientists, seeking to show the current relevance of the debate.The rediscovery of the rural family proposed in the text discussed here remains an important theoretical and methodological reference for thinking about the diversity of models and forms of organization of the rural populations, and for stressing the use of grand narratives and hermetic analytical categories in the understanding of a humanity plural

Keywords: Rural studies, peasantry, rural family, domestic groups, peasant economy. 